\title{
The impact of future demographic change on overweight and obesity, and the economic cost associated with this phenomenon, in Georgia (USA), 2000-2040
}

\author{
Nazrul Hoque*
}

\begin{abstract}
This paper examines the impact of future demographic changes on overweight and obesity, and the cost associated with overweight and obesity in Georgia, a rapidly growing and diversifying U.S. state. The number of overweight and obese adults is projected to increase from 3.7 million in 2000 to 10.2 million in 2040, an increase of 178.6 per cent. The annual costs associated with overweight and obesity is projected to increase from $\$ 6.8$ billion to $\$ 21.1$ billion, an increase of 209.8 per cent. The changes in overweight and obesity are predominantly driven by population growth, aging, and diversification of population.
\end{abstract}

Keywords: overweight, obesity, projections, prevalence, cost, Georgia.

\section{Résumé}

Cet article examine l'impact de changements démographiques futurs sur l'embonpoint et l'obésité et les coûts associés avec l'embonpoint et l'obésité en Géorgie, État où la croissance et la diversité augmentent rapidement. On projette que le nombre d'adultes obèses ou atteints d'embonpoint passera de 3,7 millions en 2000 à 10,2 millions d'ici 2040, ce qui représente une augmentation de 178,6 pour cent. Les coûts annuels associés à l'embonpoint et l'obésité devraient passer de 6,8 milliards de dollars à 21,1 milliards de dollars, soit une hausse de 209,8 pour cent. Les changements dans l'embonpoint et l'obésité sont essentiellement attribuables à la croissance, au vieillissement et à la diversification de la population.

Mots-clés : embonpoint, obésité, projections, prévalence, coûts, Géorgie.

\section{Introduction}

Overweight and obesity are serious health issues. According to the U.S. Centers for Disease Control and Prevention, obesity is the number one health problem facing America. Approximately 133.6 million American adults or 66.0 per cent of all adults are either overweight or obese (NIH 2004). Obesity rates have more than doubled since 1990, increasing from 11.6 per cent in 1990 to 26.3 per cent in 2007 (CDC 1991; CDC 2007). This increase is of considerable concern since overweight and obesity are associated with certain health risks. It has been reported that overweight and obesity are related to increased risk for heart disease, Type II diabetes, and a number of other diseases (Wolk et

\footnotetext{
* Nazrul Hoque, PhD, Department of Demography and Institute for Socioeconomic and Demographic Research, University of Texas at San Antonio, 501 West Cesar E. Chavez Blvd., San Antonio, Texas 78207-4415. E-mail: Nazrul.hoque@utsa.edu.
} 
al. 2001; Calle et al. 2003). In the United States, approximately 300,000 to 400,000 deaths are attributable to overweight and obesity each year (Allison et al. 1999; Obesity in America 2004).

In addition to observing differences in the prevalence rate of overweight and obesity for males and females (Baskin et al. 2005; Flegal et al. 2010), higher body mass indices tend to be more prevalent among minority population members due to an association between low socioeconomic status and a variety of other factors, such as historical and cultural aspects. African Americans and Hispanics tend to be more likely than non-Hispanic Whites and other groups to have higher Body Mass Index (BMI) scores. This is due, in large part, to long-term patterns of socioeconomic disparity, with African Americans and Hispanics having rates of poverty that are two to three times the level for non-Hispanic Whites, and median income levels that are roughly 60-65 per cent of those for nonHispanic Whites (U.S. Census Bureau 2009). Because of these differences, and the fact that these differences have been evident for decades, African Americans and Hispanics are more likely to purchase and consume high-calorie, high-carbohydrate foods that are generally less expensive than many lower-calorie fruits, vegetables, and lean meat alternatives. For both African Americans and Hispanics, decades of impoverishment have led to food consumption patterns based on cultural traditions and cost considerations that are likely to result in higher likelihoods of being overweight or obese.

Based on data for adults 20 years of age and older from the National Health and Nutrition Examination Survey (NHANES) 2007-2008, the age-adjusted overweight and obesity prevalence rates for Hispanics are more than six points higher, while for African Americans the prevalence rates are more than 11 points higher, compared with non-Hispanic Whites. The prevalence rates are 38.7, 44.1, and 32.4 per cent for Hispanic, African American, and non-Hispanic Whites, respectively (Flegal et al. 2010; Sturm 2004). The prevalence rates for adult population for all race/ethnicity groups are higher compared with the young population. Consequently, in areas with more diverse or aging populations, the health and financial implications can present significant concerns for policymakers and healthcare providers within these communities.

These health and financial implications may be observed in the state of Georgia. Georgia was selected for several reasons. First, the rate of overweight and obesity is very high. Georgia had the sixth-highest rate of adult obesity among all U.S. states in 2003, at 25.2 per cent, and had the ninthhighest rate of obese adults in 2007, at 28.7 per cent (CDC 2003; CDC 2007). Among Georgia adults, overweight and obesity prevalence rose from 37.0 per cent in 1984 to 64.6 per cent in 2008. This is an increase of 27.6 percentage points, and a change of almost 75 per cent, in 20 years.

Second, as mentioned before, the prevalence rates of overweight and obesity are higher for minority populations, and according to the 2010 census counts, more than 44 per cent of Georgia's population is minority (U.S. Census 2010). Thirty per cent of Georgia's population is Black and almost 9 per cent is Hispanic, and these groups are increasing rapidly. In 1990, more than 70 per cent of Georgia's population could be classified as non-Hispanic White, while in 2000 its population consisted of about 63 per cent non-Hispanic White. By 2010 this percentage has decreased to 55.9 per cent. Georgia had a larger proportion of minority population than the U.S. average. In 2000, slightly more than 28 per cent of the Georgia population was African-American, and approximately 5.3 per cent was Hispanic, while in 2010, 30 per cent of its population was African American, 8.8 was Hispanic, and the Other population accounted for almost 5.3 per cent.

Third, with a population of 9.7 million people in 2010, Georgia is the ninth most populous state and one the fastest growing states in the U.S. In terms of numerical change from 2000 to 2010, Georgia gained the third-most population after Texas and California. The increased diversity and aging of Georgia's population are similar to changes being experienced throughout the U.S. According to 
recent projections of population, minorities are expected to predominate overall in the U.S. by 2042, while Georgia is expected to reach majority minority status by 2021 or 2031, depending on projection scenarios. Examination of state-level population data for Georgia can thus offer insights relevant to national healthcare and other planning efforts.

Fourth, as indicated before, the prevalence rates of overweight and obesity are much higher for the adult population for all race/ethnicity groups, compared with the young population, and moreover, the population of Georgia is aging. The median age of the Georgia population was 25.9 years in 1970, 31.5 years in 1990, 33.4 years in 2000, and 35.3 in 2010, and is expected to increase from 35.3 years in 2010 to 38.9 years in 2040. For the Anglo population it would increase from 39.2 to 42.3 years, from 25.3 to 33.0 years for the Hispanic population, from 31.7 to 38.0 years for the Black population, and for the Other population (composed of Asians, American Indians, and other nonwhite, non-Hispanic, non-African American groups) it would increase from 30.6 to 49.6 years.

The proportion of the Georgia population aged 65 years and older is projected to increase from 13.1 per cent in 2000 to 24.1 per cent in 2040. For Anglos the proportion of population 65 years of age and above will increase from 15.5 per cent in 2000 to 27.7 per cent in 2040 . For the Black population it will increase from 9.5 per cent to 19.3 per cent. The Hispanic proportion 65 years and above will increase from 2.8 per cent to 23.0 per cent; Other population will increase from 5.6 per cent to 28.3 per cent.

McCusker et al. (2004) and Hoque et al. (2010) used a cohort-component projection model to project the number of overweight and obese adults, and the projected annual costs associated with those overweight and obese persons in Texas, through the year 2040. The study presented here uses similar data and methods to extend this analysis to the state of Georgia.

This paper demonstrates that data on the projected number of overweight and obese adults can be used not only to anticipate the costs associated with overweight and obesity but also the relative effects of population growth, change in age structure, and change in racial/ethnic composition of the population. The decomposition of total effect into the effects named above is important, as it allows us to determine the detailed causes of such increases, as well as to direct health education efforts toward those segments of the population that are most likely to experience increases in obesity - increasing the likelihood that measures can be taken to prevent or decrease the anticipated societal problems to which obesity can be attributed. This work provides a clear example of the use of applied and general demographic methods to address a critical area of concern for the nation and its individual states.

\section{Methods and materials}

A number of research methods and sources were used to obtain the necessary data to complete this study. The analysis was performed in four steps. A detailed description of each of these steps is given below.

\section{Step 1: Projecting the population of Georgia}

Population projections were computed with a cohort-component projection method, one of the most widely used techniques of population projections, which uses separate cohorts-persons with one or more common characteristics such as age, sex, and race/ethnicity - to perform separate projections of the major components of population change-fertility, mortality, and migration- 
for each cohort. These component projections are then combined in the demographic equation as follows:

$$
\mathrm{P}_{\mathrm{t}}=\mathrm{P}_{\mathrm{o}}+\mathrm{B}-\mathrm{D}+\mathrm{NM}
$$

where $\mathrm{P}_{t}=$ population for the projected year; $\mathrm{P}_{0}=$ population at the base year; $\mathrm{B}=$ births between $\mathrm{P}_{0}$ and $\mathrm{P}_{t} ; \mathrm{D}=$ deaths between $\mathrm{P}_{0}$ and $\mathrm{P}_{\mathrm{t}}$; and $\mathrm{NM}=$ net migration between $\mathrm{P}_{0}$ and $\mathrm{P}_{\mathrm{t}}$.

The following major steps were performed for the population projections: (1) a baseline set of cohorts was selected for the population of Georgia for the baseline time period; (2) appropriate baseline fertility, mortality, and migration measures were determined for each cohort for the baseline time period; (3) a method was determined for projecting trends in fertility, mortality, and migration rates over the projection period; and (4) SAS was used to apply the rates to the baseline cohorts in order to project the population of Georgia through 2040.

The four baseline cohorts used in the projections were single-year age cohorts of male and female Anglos (White non-Hispanic persons), Blacks (Black non-Hispanics), Hispanics (Spanish-origin persons of all racial and ethnic groups), and Other (all other non-Anglo, non-African-American, non-Hispanic racial and ethnic groups). These cohorts were extracted from the Summary File 1 of the 2000 Census of Population and Housing. A detailed description of the methods for formulating these race/ethnicity combinations and the projections methodology can be obtained from the author.

Baseline age and race/ethnicity-specific fertility rates were computed with data from the Georgia Department of State Health Services for births by age and race/ethnicity, and by the mother's place of residence. The numerators for such rates are the average number of births for 1999, 2000, and 2001 for mothers in each age and race/ethnicity group, and the denominators are the population counts by age and race/ethnicity in 2000 . These data showed total fertility rates for the Anglo, Black, Hispanic, and Other racial/ethnic groups in 2000 that were 1.96, 2.14, 3.41, and 2.12, respectively, for the state of Georgia. To project fertility rates, we examined the 1990 total fertility rates by race/ ethnicity, and decided to use the 2000 constant total fertility rates by race/ethnicity for the projected periods. The reason being that Anglo total fertility rates were 1.81 in 1990 and increased to 1.96 in 2000. The Black total fertility rates decreased from 2.44 in 1990 to 2.14 in 2000 . The total fertility rates for Hispanics increased from 2.46 in 1990 to 3.40 in 2000, and for the Other category, total fertility rates increased from 1.84 in 1990 to 1.88 in 2000. The total fertility rate increased from 2.03 in 1990 to 2.12 in 2000 . We also reviewed total fertility at the national level, whose rates varied from 2.02 in 2000 to 2.06 in 2010 and 2015, and 2.03 in 2050 (U.S. Census Bureau 2008).

Survival rates by age, sex, and race/ethnicity were computed using the death data from the Georgia Department of Health for 1999, 2000, and 2001, and from the 2000 census. Survival rates were projected assuming that the survival rates of Georgia will follow national trends for the projection period. We computed the ratio of Georgia's age, sex, and race/ethnicity specific survival rates at 2000 to those of the nation, and applied those ratios to the projected survival rates for the U.S. The national rates were obtained from the Population Projections Branch of the U.S. Bureau of the Census (Spencer 1984, 1986, 1989; Hollmann et al. 2000).

Migration is the most difficult component of population projections for which base rates and projected rates are obtained. We used a vital statistics method that is the simplest and most accurate for estimating net migration. In this method, net migration is equal to population change minus natural increase (births minus deaths). Thus, births and deaths by age, sex, and race/ethnicity were added to, and subtracted from, the 1990 population to produce an expected 2000 population. This expected 
Hoque: Impact of future demographic change on overweight and obesity in Georgia, 2000-2040

population was compared to the actual 2000 census counts, to estimate net migration rates for the 1990-2000 periods. These rates provided the migration component for population projections.

Four alternative population projection scenarios were developed, based on alternative migration rates. These scenarios used the same fertility and survival assumptions, but three different sets of assumptions regarding migration. One scenario assumed no net migration (which means that the net of in- and out-migration is equal to zero) by age, sex, and race/ethnicity, referred to as the 0.0 migration scenario. A second scenario assumed that rates of age, sex, and race/ethnicity specific net migration were equal to one half of the 1990-2000 rates, referred to as the 0.5 migration scenario. A third scenario assumed a continuation of the 1990-2000 rates of age, sex, and race/ethnicity-specific net migration, referred to as the 1.0 migration scenario. A fourth scenario assumed a continuation of the 2000-2007 rates of age, sex, and race/ethnicity-specific net migration, referred to as the 2000-2007 migration scenario. Migration rates for 2000-2007 are based on the 2007 estimated population by age, sex, and race/ethnicity. (For a detailed discussion on population projections, refer to the projection methodology, which can be obtained from the author.)

The 2000-2007 scenario is used for this analysis because it is the scenario utilizing the most recent patterns of migration, and is believed to be the most likely to characterize the future population of Georgia. The projected population produced by different scenarios was compared with the census counts of the 2010 population, and the 2000-2007 scenario was closest to the actual counts. However, as with all population projections, if the assumptions employed about future demographic processes are incorrect, the projections will be inaccurate. The specific assumptions of the 2000-2007 scenario are as follows: An average of 115,000 to 120,000 persons per year will migrate (net-migration) throughout the projection period. For the projection period, total fertility rates were projected to remain at 2.1. Survival rates for Georgia were assumed to follow the national level (i.e., life expectancy will increase by 6 years from 2000 to 2040). If these assumptions are incorrect, the projections will be incorrect. We utilized these projections with full realization of their limitations but with the expectation that although the exact number of persons projected to live in the state of Georgia in the future is unlikely to be correct, the general trends are likely to point in the direction indicated by this analysis.

\section{Step 2: Prevalence of overweight and obesity}

We computed overweight and obesity rates by using the body mass index (BMI) indicator, which is calculated by dividing the weight of a person in kilograms by the square of the person's height in meters. Using the definition of the National Institutes of Health (1998), individuals are classified as being overweight or obese by having a body mass index (BMI) between 25.0 and 29.9, and equal to or greater than $30.0 \mathrm{~kg} / \mathrm{m}^{2}$, respectively. We used 1999-2002 Behavioral Risk Factor Surveillance System (BRFSS) data for Georgia to compute overweight and obesity rates by age, sex, and race/ ethnicity. BRFSS is a state-based health survey that was established in 1984 by the Center for Disease Control and Prevention (CDC) with the cooperation of state health departments. The BRFSS is a random-digit-dialed ongoing telephone survey conducted by the U.S. states, the District of Columbia, Puerto Rico, and the U.S. Virgin Islands (CDC 1991, 2000, 2001, 2002). BRFSS obtains information about health risk behaviors, clinical preventive health practices, and healthcare access, primarily related to chronic disease and injury from a representative sample of adults in each state. The questionnaire content varies somewhat from year to year, with few changes in the core content. Sample sizes may vary by year and state, but are designed to be large enough in each year to reliably estimate most rates. 
Georgia has participated in the BRFSS since 1984. The Georgia BRFSS used Disproportionate Stratified Sample (DSS) design. Telephone numbers were classified into two strata, based on the presumed density of residential telephone numbers. Telephone numbers in high-density strata were sampled at a higher rate than the telephone numbers in low-density strata. Respondents were randomly selected from among the adult members of non-institutional households. At the end of the survey year, data from the monthly surveys were compiled and weighted to represent the age, sex, and race/ethnicity distribution of the adult population of Georgia. The sample size was 2,258, 4,114, 4,532, and 5,065 for the years 1999, 2000, 2001, and 2002, respectively.

Respondents' selfreported height and weight were used to calculate their BMI, applying the method described above. Pregnant women were excluded from the analysis. In order to stabilize the prevalence rates by age group, sex, and race/ethnicity, we used a four-year average rate, because the overweight and obesity rates fluctuated greatly from year to year. We also computed national rates, and compared Georgia's obesity rates with the national rates. If Georgia's overweight and obesity rates were missing for any age groups in any race/ethnicity, then we substituted the missing rates from the national rates. If the overweight and obesity rates for any age groups for any race/ethnicity were higher/lower than 20 per cent of the national rates, we also substituted those rates. This happened for the Hispanic and Other groups because of the small proportion of the sample. The age-, sex-, and race/ethnicity-specific prevalence rates used for overweight and obesity are presented in Table 1.

Table 1. Prevalence rate (per 100) of overweight and obese adults in Georgia by age group, sex, and race/ethnicity, 1999-2002.

\begin{tabular}{ccccccccc}
\hline & \multicolumn{4}{c}{ Male } & \multicolumn{4}{c}{ Female } \\
\cline { 2 - 9 } \multicolumn{2}{c}{ Anglo } & \multicolumn{1}{c}{ Black } & Hispanic & Other & Anglo & Black & Hispanic & Other \\
\hline Overweight & & & & & & & \\
$18-24$ & 30.8 & 32.6 & 32.7 & 26.2 & 16.5 & 27.2 & 21.9 & 15.7 \\
$25-34$ & 44.9 & 43.7 & 50.4 & 39.5 & 21.2 & 30.3 & 27.9 & 17.7 \\
$35-44$ & 48.1 & 44.2 & 49.0 & 39.6 & 26.7 & 34.9 & 32.1 & 26.5 \\
$45-54$ & 47.9 & 45.0 & 46.6 & 42.1 & 28.5 & 35.3 & 37.1 & 30.4 \\
$55-64$ & 48.8 & 45.9 & 53.4 & 53.0 & 33.2 & 34.8 & 36.2 & 31.6 \\
$65+$ & 47.2 & 44.4 & 44.1 & 37.1 & 32.5 & 39.9 & 35.9 & 29.1 \\
Obese & & & & & & & & \\
$18-24$ & 17.0 & 16.2 & 15.2 & 9.2 & 12.4 & 22.2 & 17.7 & 9.3 \\
$25-34$ & 19.0 & 28.9 & 21.3 & 13.6 & 19.5 & 34.0 & 24.2 & 13.1 \\
$35-44$ & 23.0 & 34.5 & 26.0 & 15.1 & 23.7 & 40.7 & 32.3 & 18.2 \\
$45-54$ & 27.6 & 28.5 & 31.3 & 18.6 & 27.4 & 43.6 & 31.4 & 20.4 \\
$55-64$ & 25.7 & 27.2 & 26.5 & 17.3 & 27.8 & 47.8 & 32.3 & 16.7 \\
$65+$ & 17.6 & 26.9 & 21.9 & 17.5 & 21.2 & 36.3 & 26.5 & 16.4 \\
\hline
\end{tabular}

As shown in Table 1, overall the prevalence of overweight is higher for males compared with females for all race/ethnicity groups. The prevalence of overweight for Anglo males is almost double for the age groups between 18 and 44 when compared to Anglo females, while the lowest difference can be observed in the 65+ age group-however, that difference is still more than 45 per cent. The prevalence of overweight is also higher for Black males than Black females for all age groups. For the Hispanic and Other populations we observed similar patterns (i.e., male rates higher than female rates).

The obesity for Anglo males is more or less similar to that of Anglo females, except in the age groups 18-24 and 65+. Obesity rates are higher for the 18-24-age Anglo males, while female rates 
Hoque: Impact of future demographic change on overweight and obesity in Georgia, 2000-2040

are higher for the age groups 55-64 and 65+. The obesity rates for Black females are higher compared with Black males across all age groups. The greatest difference by sex in obesity prevalence among Blacks can be observed in the 55-64 age group, where the prevalence for females is almost twice as high as for males (47.8 per cent for females, 27.2 per cent for males). The same pattern can be observed for Hispanic males and females for the same age group (i.e., female obesity rate is significantly higher than male rate). For the Other population, the obesity rate is higher for females in the middle age groups compared with males. Overall, the prevalence of overweight is higher for males compared with females, while the prevalence of obesity is higher for females compared with males for all race/ethnicity groups.

\section{Projected changes in the prevalence of overweight and obesity}

Over the past 20 years, the prevalence rates of overweight and obesity have increased considerably in the U.S. This increase has been so rapid during recent years that it is not likely to be sustainable over time. For this reason, the future rates of change in the prevalence of overweight and obese adults were assumed to slow down over time. Changes in the prevalence of overweight and obesity were based on data from the 1999-2010 national BRFSS and 1999-2008 NHANES. According to NHANES data, the prevalence of overweight remained the same from 2000 to 2008, while the prevalence of obesity increased from 30.9 per cent to 34.3 per cent (i.e., an increase of 11 per cent). We assume that the rates of change in prevalence of obesity will increase linearly from 2000 to 2010 by 10 per cent overall, and then slow down over time. We also assume that from 2010 to 2020 and 2020 to 2030 the prevalence rate of obesity will increase by 5 per cent for each decade, respectively, instead of 10 per cent. For overweight we use the constant rate of 1999-2002. For comparison purposes, another set of projections was computed using linear rates for prevalence of obesity, based on 1999-2010 BRFSS data. Due to space limitations, we do not present here the results for the latter set of projections.

\section{Step 3: Projected costs of obesity}

The expected costs associated with obesity used in the projection were derived from previously published estimated costs associated with obesity for Georgia. According to a study by Finkelstein et al. (2004), the cost estimate for obesity was $\$ 2.1$ billion for the year 2003 , leading to an annual amount of $\$ 1,431.15$ per obese adult person in Georgia. A recent study by Dor et al. (2010) estimates the yearly cost at $\$ 432$ for an overweight man, $\$ 524$ for an overweight woman, $\$ 2,646$ for an obese man, and $\$ 4,879$ for an obese woman. Since this is a recent study, we use these 2010 values to project the future cost associated with overweight and obesity in Georgia. These are direct medical costs, which include both out-of-pocket and insurance-covered expenditures related to physician services, hospital care, and pharmaceuticals. We have not added indirect expenses or the value of lost life to these annual costs. Adding the value of lost life would produce much higher costs. According to Dor et al. (2010), including the values for loss of life would increase the estimated costs to $\$ 8,365$ for obese women and $\$ 6,518$ for obese men.

\section{Step 4: Decomposition analysis}

Finally, decomposition techniques were used to identify how each of the three factors studiedpopulation change, aging, and diversification — affected changes in the number of overweight and 
obese adults relative to the population base. Decomposition analysis is a technique for identifying the proportion of a difference between two crude rates that is attributable to each of a set of demographic factors (Kitagawa 1955; Das Gupta 1978). Decomposition analysis is clearly an appropriate technique for discerning how demographic factors will affect the number of obese adults in Georgia at different points in time. By using decomposition techniques, it is possible to discern what part of the change in the number of obese adults for each of the four time periods (2000-2010, 2010-2020, 2020-2040, and 2000-2040) is attributable to population change, aging, and diversification.

\section{Results}

In Georgia, all four population projection scenarios were used to project the number of overweight and obese adults, and the direct costs associated with overweight and obesity in Georgia, from 2000 to 2040. Due to space limitations, the data presented here are for the 2000-2007 migration scenario. The 2000-2007 scenario is used for this analysis, because it is the scenario that uses the most recent patterns of migration, and because it produced the closest population compared with the 2010 census counts, and so is believed to most accurately approximate future levels of population change in Georgia. Detailed data for all four scenarios can be obtained from the author.

\section{An overview of major demographic trends}

Table 2 provides data on the adult population (18 years of age and older) in Georgia by age, sex, and race/ethnicity for 2000 and projected to 2040. It is divided into five panels. Panel I shows the projected adult population by size. The adult population in Georgia is expected to increase from 6 million in 2000 to approximately 15 million in 2040 . The adult population by race/ethnicity is projected to increase from 2000 to 2040 as follows: the non-Hispanic White or Anglo population will increase from 4.0 to 6.0 million, the Black population will increase from 1.6 to 4.5 million, the Hispanic population will increase from 299,258 persons to 3.2 million, and the Other population will increase from 153,845 persons to 1.0 million (Table 2, Panel I).

The total adult population is projected to increase by 144.8 per cent from 2000 to 2040 . Although all racial/ethnic groups show population increase during this time, the Anglo population will only increase by 50.7 per cent, while the Black population will increase by 182.8 per cent, the Hispanic population will increase by 972.2 per cent, and the Other population will increase by 556.5 per cent. The Anglo adult population would account for only 23 per cent of net growth from 2000 to 2040, which means the remaining 77 per cent of net growth can be attributed to factors among the minority populations (Table 2, Panel II).

\section{Increase in minority population}

The second major demographic pattern is the trend toward an increasing number and proportion of minority population. Panel III of Table 2 presents the per cent of the adult population (18 years of age and older) in Georgia by race/ethnicity for 2000, and projected to 2040. The proportion of the Black adults is expected to increase from 26.7 per cent in 2000 to 30.9 per cent in 2040. The proportion of Hispanic adults is expected to increase from 5.0 per cent in 2000 to 21.8 per cent in 2040. The same holds true for the proportion of Other adults: it will increase from 2.6 per cent in 2000 to 6.9 per cent in 2040. The proportion of Anglo population is expected decrease from 65.7 per cent in 2000 to 40.4 per cent in 2040. 
Table 2. Size, change, and characteristics of adult population (18 years of age and older) by race/ethnicity in Georgia in 2000 and projected to 2040 (2000-2007 projection scenario).

\begin{tabular}{|c|c|c|c|c|c|}
\hline Year & Anglo & Black & Hispanic & Other & Total \\
\hline \multicolumn{6}{|c|}{ Panel I: Population size } \\
\hline 2000 & $3,956,327$ & $1,607,789$ & 299,258 & 153,845 & $6,017,219$ \\
\hline 2010 & $4,491,407$ & $2,189,903$ & 540,654 & 264,215 & $7,486,179$ \\
\hline 2020 & $5,024,671$ & $2,863,089$ & 995,843 & 434,167 & $9,317,770$ \\
\hline 2030 & $5,520,320$ & $3,647,513$ & $1,813,043$ & 680,349 & $11,661,225$ \\
\hline 2040 & $5,961,930$ & $4,546,684$ & $3,208,643$ & $1,009,951$ & $14,727,208$ \\
\hline \multicolumn{6}{|c|}{ Panel II: per cent change in population for selected time periods } \\
\hline $2000-2010$ & 13.5 & 36.2 & 80.7 & 71.7 & 24.4 \\
\hline $2010-2020$ & 11.9 & 30.7 & 84.2 & 64.3 & 24.5 \\
\hline $2020-2030$ & 9.9 & 27.4 & 82.1 & 56.7 & 25.2 \\
\hline $2030-2040$ & 8.0 & 24.7 & 77.0 & 48.4 & 26.3 \\
\hline $2000-2040$ & 50.7 & 182.8 & 972.2 & 556.5 & 144.8 \\
\hline \multicolumn{6}{|c|}{ Panel III: per cent of population by race/ethnicity in Texas in 2000 and projected to 2040} \\
\hline 2000 & 65.7 & 26.7 & 5.0 & 2.6 & 100.0 \\
\hline 2010 & 60.0 & 29.3 & 7.2 & 3.5 & 100.0 \\
\hline 2020 & 53.9 & 30.7 & 10.7 & 4.7 & 100.0 \\
\hline 2030 & 47.4 & 31.3 & 15.5 & 5.8 & 100.0 \\
\hline 2040 & 40.4 & 30.9 & 21.8 & 6.9 & 100.0 \\
\hline
\end{tabular}

Panel IV: per cent of population by age group and race/ethnicity in 2000 and projected to 2040 2000

\begin{tabular}{|c|c|c|c|c|c|}
\hline $18-24$ & 11.6 & 16.7 & 28.9 & 15.8 & 13.9 \\
\hline $25-34$ & 19.3 & 23.9 & 35.8 & 28.7 & 21.6 \\
\hline $35-44$ & 21.9 & 24.2 & 19.7 & 24.1 & 22.5 \\
\hline $45-54$ & 19.1 & 17.0 & 8.9 & 17.1 & 18.0 \\
\hline $55-64$ & 12.6 & 8.7 & 3.9 & 8.7 & 10.9 \\
\hline $65+$ & 15.5 & 9.5 & 2.8 & 5.6 & 13.1 \\
\hline \multicolumn{6}{|l|}{2040} \\
\hline $18-24$ & 10.8 & 12.8 & 13.4 & 8.3 & 11.8 \\
\hline $25-34$ & 15.9 & 18.5 & 18.4 & 14.3 & 17.1 \\
\hline $35-44$ & 16.1 & 17.6 & 16.9 & 16.6 & 16.8 \\
\hline $45-54$ & 15.7 & 17.8 & 11.2 & 15.9 & 15.4 \\
\hline $55-64$ & 13.8 & 14.0 & 17.1 & 16.6 & 14.8 \\
\hline $65+$ & 27.7 & 19.3 & 23.0 & 28.3 & 24.1 \\
\hline \multicolumn{6}{|c|}{ anel V: Per cent change in population age group and race/ethnicity from 2000-2040 } \\
\hline $18-24$ & 40.6 & 115.8 & 397.5 & 244.1 & 107.4 \\
\hline $25-34$ & 23.8 & 119.5 & 450.5 & 226.7 & 94.2 \\
\hline $35-44$ & 10.9 & 106.0 & 821.9 & 353.8 & 83.0 \\
\hline $45-54$ & 23.7 & 196.0 & 1247.6 & 507.8 & 109.3 \\
\hline $55-64$ & 66.0 & 357.9 & 4644.1 & 1160.4 & 229.5 \\
\hline
\end{tabular}

\section{The aging population}

The projected per cents of population by age group and race/ethnicity from 2000 to 2040 for Georgia are provided in Panel IV of Table 2. The proportion of population 65 years of age or older is projected to increase from 13.1 per cent in 2000 to 24.1 per cent in 2040. During this period, the proportion of the population 65 years of age or older within each race/ethnicity is projected to increase as follows: the Hispanic population will increase from 2.8 per cent to 23.0 per cent, the Black 
population will increase from 9.5 per cent to 19.3 per cent, the Anglo population will increase from 15.5 per cent to 27.7 per cent, and the Other population will increase from 5.6 per cent to 28.3 per cent.

In addition, it can be seen that the proportions of persons aged 55-64 as well as 65+ for the total adult population of Georgia are expected to increase, while the proportion of all other adult age groups is projected to decrease. This can also be observed for Anglos and for Others while Blacks and Hispanics have an increase in population proportion of persons aged 45 and higher. The aging of the adult population is more pronounced for Anglos and Others than that of Hispanics or Blacks.

Panel V of Table 2 shows the per cent change in population from 2000 to 2040 by age group and race/ethnicity. For the total population as well as for each race/ethnicity, the already mentioned population growth can be seen. This can be observed in each age group, yet with great differences in the per cent change, the younger age groups are expected to grow considerably less than the older age groups. As noted before, the Anglo population is expected to grow the least (as measured in per cent change), while the population that is Hispanic has the highest per cent change within all age groups from 2000 to 2040.

\section{Impacts of demographic change on overweight and obesity}

The adult population that is projected to be overweight and obese in Georgia is given in Table 3. The total number of overweight adults in Georgia is projected to increase from 2.2 million in 2000 to 5.5 million in 2040. The Anglo overweight population will increase from 1.4 to 2.2 million, the Black population will increase from 0.60 to 1.7 million, the Hispanic population will increase from 0.12 to 1.3 million, and the Other category of overweight persons will increase from 47,800 to 339,700.

The number of obese persons in the adult population is projected to increase from 1.5 million in 2000 to 4.7 million in 2040. During this same time, the Anglo obese adult population will increase from 0.88 to 1.6 million, the Black population will increase from 0.53 million to 1.9 million, the Hispanic population will increase from 68,400 to 1.0 million, and the Other category of obese persons will increase from 23,200 to 203,500. For the total adult population, this means that the percentage of the population that is obese is projected to increase from 24.8 per cent in 2000 to 32.1 per cent in 2040. The percentage of the population that is overweight will increase slightly due to aging, because we used the same rate for 2040.

Panel II of Table 3 presents the per cent change in overweight and obese persons for selected time periods in Georgia. The total overweight adult population will increase by 152.7 per cent, and the obese population will increase by 216.3 per cent from 2000 to 2040 . The total overweight and obese population will change by 178.6 per cent. During the projection period, the overweight Anglo adult population will increase by 53.0 per cent, the overweight Black adult population will increase by 189.2 per cent, the overweight Hispanic adult population will increase by 996.3 per cent, and the overweight Other adult population will increase by 610.8 per cent. The per cent change in persons with obesity follows similar patterns, with Hispanics having the highest per cent change and Anglos having the smallest per cent change. The per cent change in overweight and obesity decreases steadily over time for all race/ethnicity groups.

The proportion of overweight adults who are Anglo will decrease from 64.9 per cent in 2000 to 39.3 per cent in 2040, while the proportion of overweight Blacks will increase from 27.6 per cent in 2000 to 31.6 per cent in 2040, the proportion of overweight Hispanics will increase from 5.3 per cent in 2000 to 22.9 per cent in 2040, and the proportion of overweight Others is projected to increase from 2.2 per cent in 2000 to 6.2 per cent in 2040 (Table 3, Panel III). The proportion of Anglo obese 
adults will decrease from 58.7 per cent in 2000 to 34.3 in 2040. The proportion of Black obese adults will increase from 35.1 per cent in 2000 to 39.9 per cent in 2040. The proportion of the Hispanic obese population will increase from 4.6 to 21.5 , and Other obese population will increase from 1.6 per cent to 4.3 per cent from 2000 to 2040 (Table 3, Panel III).

Table 3. Adult population that is overweight or obese in Georgia in 2000 and projected to 2040 by race/ethnicity (2000-2007 projection scenario).

\begin{tabular}{|c|c|c|c|c|c|c|c|c|c|c|}
\hline \multirow[b]{2}{*}{ Year } & \multicolumn{4}{|c|}{ Overweight } & \multicolumn{4}{|c|}{ Obese } & \multicolumn{2}{|c|}{ Total } \\
\hline & Anglo & Black & Hispanic & Other & Anglo & Black & Hispanic & Other & Overweight & Obese \\
\hline \multicolumn{11}{|c|}{ Panel I: Overweight and obese population (in thousands) } \\
\hline $2000 \quad 1$ & $1,414.4$ & 600.8 & 115.2 & 47.8 & 879.0 & 525.0 & 68.4 & 23.2 & $2,178.2$ & $1,495.6$ \\
\hline 2010 & $1,619.8$ & 821.3 & 219.5 & 86.0 & $1,108.7$ & 793.4 & 150.5 & 45.9 & $2,746.6$ & $2,098.5$ \\
\hline 2020 & $1,822.0$ & $1,084.1$ & 396.3 & 144.7 & $1,325.6$ & $1,133.5$ & 307.7 & 83.1 & $3,447.1$ & $2,849.9$ \\
\hline 2030 & $2,004.9$ & $1,389.2$ & 718.2 & 229.4 & $1,508.5$ & $1,516.2$ & 583.6 & 136.3 & $4,341.7$ & $3,744.6$ \\
\hline 2040 & $2,163.7$ & $1,737.3$ & $1,262.5$ & 339.7 & $1,624.8$ & $1,885.9$ & $1,016.2$ & 203.5 & $5,503.2$ & $4,730.4$ \\
\hline \multicolumn{11}{|c|}{ Panel II: Per cent change in overweight or obese persons for selected time periods } \\
\hline $2000-2010$ & 14.5 & 36.7 & 90.6 & 80.0 & 26.1 & 51.1 & 120.0 & 98.0 & 26.1 & 40.3 \\
\hline $2010-2020$ & 12.5 & 32.0 & 80.6 & 68.2 & 19.6 & 42.9 & 104.4 & 80.9 & 25.5 & 35.8 \\
\hline $2020-2030$ & 10.0 & 28.1 & 81.2 & 58.5 & 13.8 & 33.8 & 89.7 & 64.1 & 26.0 & 31.4 \\
\hline $2030-2040$ & 7.9 & 25.1 & 75.8 & 48.1 & 7.7 & 24.4 & 74.1 & 49.3 & 26.8 & 26.3 \\
\hline $2000-2040$ & 53.0 & 189.2 & 996.3 & 610.8 & 84.8 & 259.2 & 1384.9 & 777.2 & 152.7 & 216.3 \\
\hline \multicolumn{11}{|c|}{ Panel III: Perc ent of population by race/ethnicity in Georgia in 2000 and projected to 2040} \\
\hline 2000 & 64.9 & 27.6 & 5.3 & 2.2 & 58.7 & 35.1 & 4.6 & 1.6 & 100.0 & 100.0 \\
\hline 2010 & 59.0 & 29.9 & 8.0 & 3.1 & 52.8 & 37.8 & 7.2 & 2.2 & 100.0 & 100.0 \\
\hline 2020 & 52.9 & 31.4 & 11.5 & 4.2 & 46.5 & 39.8 & 10.8 & 2.9 & 100.0 & 100.0 \\
\hline 2030 & 46.2 & 32.0 & 16.5 & 5.3 & 40.3 & 40.5 & 15.6 & 3.6 & 100.0 & 100.0 \\
\hline 2040 & 39.3 & 31.6 & 22.9 & 6.2 & 34.3 & 39.9 & 21.5 & 4.3 & 100.0 & 0.0 \\
\hline \multirow{2}{*}{\multicolumn{11}{|c|}{$\begin{array}{l}\text { Panel IV: Per cent of population by age group and race/ethnicity in } 2000 \text { and projected to } 2040 \\
2000\end{array}$}} \\
\hline & & & & & & & & & & \\
\hline $18-24$ & 7.7 & 13.4 & 21.8 & 10.7 & 7.7 & 9.9 & 20.3 & 9.6 & 10.1 & 9.1 \\
\hline $25-34$ & 18.0 & 23.3 & 39.3 & 26.4 & 16.7 & 23.1 & 35.0 & 25.4 & 20.7 & 19.9 \\
\hline $35-44$ & 22.9 & 25.4 & 21.7 & 25.5 & 23.1 & 28.0 & 24.6 & 26.7 & 23.7 & 24.9 \\
\hline $45-54$ & 20.4 & 18.1 & 9.8 & 19.8 & 23.5 & 19.1 & 12.1 & 22.2 & 19.1 & 21.5 \\
\hline $55-64$ & 14.3 & 9.2 & 4.5 & 11.7 & 15.2 & 10.3 & 5.0 & 9.8 & 12.4 & 12.9 \\
\hline $65+$ & 16.7 & 10.6 & 2.9 & 5.9 & 13.8 & 9.6 & 3.0 & 6.3 & 14.0 & 11.7 \\
\hline \multicolumn{11}{|l|}{2040} \\
\hline $18-24$ & 7.1 & 10.0 & 9.4 & 5.2 & 7.3 & 7.3 & 8.7 & 4.7 & 8.4 & 7.5 \\
\hline $25-34$ & 14.5 & 17.9 & 18.3 & 12.3 & 14.0 & 17.6 & 16.4 & 11.8 & 16.3 & 15.8 \\
\hline $35-44$ & 16.6 & 18.1 & 17.3 & 16.5 & 17.2 & 20.0 & 19.6 & 17.1 & 17.3 & 18.9 \\
\hline $45-54$ & 16.5 & 18.5 & 11.8 & 17.2 & 19.7 & 19.6 & 13.8 & 19.1 & 16.1 & 18.4 \\
\hline $55-64$ & 15.5 & 14.6 & 19.9 & 21.1 & 17.0 & 16.5 & 19.6 & 17.6 & 16.5 & 17.3 \\
\hline $65+$ & 29.8 & 20.9 & 23.3 & 27.7 & 24.8 & 19.0 & 21.9 & 29.7 & 25.4 & 22.1 \\
\hline \multicolumn{11}{|c|}{ Panel V: Per cent change in population that is overweight or obese, 2000-2040 } \\
\hline $18-24$ & 40.5 & 116.7 & $7 \quad 370.7$ & 244.8 & 75.3 & $3 \quad 167.2$ & 535.1 & 329.4 & 110.8 & 161.7 \\
\hline $25-34$ & 23.8 & 121.1 & 412.3 & 231.9 & 54.4 & 172.8 & 598.0 & 307.8 & 98.8 & 151.3 \\
\hline $35-44$ & 10.8 & 106.6 & 774.6 & 359.6 & 38.4 & 156.4 & 1082.3 & 462.6 & 84.4 & 139.0 \\
\hline $45-54$ & 23.8 & 196.2 & 1216.3 & 518.0 & 54.3 & 268.7 & 1581.6 & 654.7 & 112.3 & 170.6 \\
\hline $55-64$ & 65.9 & 356.0 & 4698.3 & 1177.2 & 107.1 & 475.8 & 5781.7 & 1473.8 & 238.6 & 325.8 \\
\hline $65+$ & 172.6 & 472.1 & 8764.1 & 3251.2 & 232.4 & 611.5 & 10730.4 & 4033.4 & 356.5 & 496.5 \\
\hline
\end{tabular}

The aging of the population will noticeably affect the prevalence rates of overweight and obesity by age group in the projected years. The effects of aging are apparent for almost all racial and ethnic groups. The prevalence of overweight is expected to increase from 12.4 to 16.5 per cent for the age group 55-64, and from 14.0 to 25.4 per cent for $65+$. The prevalence of obesity is going to increase from 12.9 to 17.3 per cent for age group 55-64, and from 11.7 to 22.1 per cent for 65+ from 2000 
to 2040. The largest increase in overweight and obesity for all race/ethnicity groups is predicted for those who are 55 years of age and older (Table 3, Panel V). For the age group 65+, the overweight population will increase by 356.5 per cent, and the obese population will increase by 496.5 per cent, from 2000 to 2040. The greatest changes can be observed for Hispanics and Other populations.

Table 4. Projected cost associated with overweight and obesity in Georgia by race/ethnicity from 20002040 under 2000-2007 projection scenario (using 2009 constant dollars and in millions).

\begin{tabular}{|c|c|c|c|c|c|c|c|c|c|c|c|}
\hline \multirow[b]{2}{*}{ Year } & \multicolumn{4}{|c|}{ Overweight } & \multicolumn{4}{|c|}{ Obese } & \multicolumn{3}{|c|}{ Total } \\
\hline & Anglo & Black & Hispanic & Other & Anglo & Black & Hispanic & Other & Overweight & Obese & Cost \\
\hline 2000 & 661.0 & 286.3 & 52.8 & 22.4 & $3,344.7$ & $2,109.9$ & 245.4 & 88.8 & $1,022.5$ & $5,788.8$ & $6,811.3$ \\
\hline 2010 & 757.5 & 391.6 & 101.1 & 40.3 & $4,218.4$ & $3,202.5$ & 547.2 & 175.3 & $1,290.5$ & $8,143.4$ & $9,433.9$ \\
\hline 2020 & 52.5 & 517.2 & 184.0 & 67.8 & 5,0 & $4,584.4$ & & 315.3 & & 11,09 & 2.5 \\
\hline 2030 & 938.6 & 663.2 & 335.4 & 107.3 & $5,760.9$ & $6,132.9$ & $2,199.1$ & 514.0 & $2,044.5$ & $14,606.9$ & $16,651.4$ \\
\hline 2040 & $1,013.0$ & 829.4 & 592.5 & 158.9 & $6,206.7$ & $7,627.6$ & $3,907.5$ & 764.4 & $2,593.8$ & $18,506.2$ & $21,100.0$ \\
\hline
\end{tabular}

The projected annual costs associated with overweight and obesity are given in Table 4. The overall costs of overweight and obesity are expected to increase by about 209.8 per cent, from $\$ 6.8$ billion in 2000 to about $\$ 21.1$ billion in 2040 . During this period, the annual costs associated with overweight and obesity by race/ethnicity are projected to increase as follows: for the Anglo population, costs will increase from $\$ 4.0$ billion to $\$ 7.2$ billion, for the Black population it will increase from $\$ 2.4$ billion to $\$ 8.5$ billion, for the Hispanic population it will increase from $\$ 0.23$ billion to $\$ 4.5$ billion, and for the Other population it will increase from $\$ 0.11$ billion to $\$ 0.92$ billion. In terms of per cent change, the projected costs associated with overweight and obesity will increase by about 80.2 per cent for Anglos, by 1,409.1 per cent for Hispanics, by 252.9 per cent for Blacks, and by 730.3 per cent for the Other population from 2000 to 2040.

\section{Results of the decomposition analysis}

The results of the decomposition analysis of population change by age and race/ethnicity on overweight and obesity prevalence in Georgia are shown in Table 5. The first column shows the total effect of the three factors combined on the differences in the crude rates of overweight and obesity for the time period indicated. The next three columns decompose the difference in the crude rates due to population change (referred to as rate effect), age, and race/ethnicity.

Table 5. Decomposition of the effects of population change, age, and race/ethnicity on overweight and obesity in Georgia under 2000-2007 projection scenario.

\begin{tabular}{|c|c|c|c|c|c|c|c|c|c|c|}
\hline \multirow{2}{*}{$\begin{array}{l}\text { Charac- } \\
\text { teristic }\end{array}$} & \multirow{2}{*}{$\begin{array}{l}\text { Total } \\
\text { effect }\end{array}$} & \multicolumn{3}{|c|}{ Composition effect due to } & \multicolumn{3}{|c|}{$\begin{array}{l}\text { Percent of change in total } \\
\text { effect due to }\end{array}$} & \multicolumn{3}{|c|}{$\begin{array}{l}\text { Percent of absolute change } \\
\text { in total effect due to }\end{array}$} \\
\hline & & $\begin{array}{l}\text { Rate } \\
\text { effect }\end{array}$ & Age & $\begin{array}{c}\text { Race/ } \\
\text { ethnicity }\end{array}$ & $\begin{array}{l}\text { Rate } \\
\text { effect }\end{array}$ & Age & $\begin{array}{c}\text { Race/ } \\
\text { ethnicity }\end{array}$ & $\begin{array}{l}\text { Rate } \\
\text { effect }\end{array}$ & Age & $\begin{array}{c}\text { Race/ } \\
\text { ethnicity }\end{array}$ \\
\hline 2000-2010 & & & & & & & & & & \\
\hline Overweight & 0.4919 & 0.0196 & 0.3390 & 0.1333 & 3.99 & 68.91 & 27.09 & 3.99 & 68.91 & 27.09 \\
\hline Obese & 3.1745 & 2.5177 & 0.3458 & 0.3110 & 79.31 & 10.89 & 9.80 & 79.31 & 10.89 & 9.80 \\
\hline 2010-2020 & & & & & & & & & & \\
\hline Overweight & 0.3059 & -0.0177 & 0.1965 & 0.1270 & -5.78 & 64.26 & 41.52 & 5.18 & 57.60 & 37.22 \\
\hline $\begin{array}{l}\text { Obese } \\
2020-2040\end{array}$ & 2.5528 & 2.2552 & -0.0069 & 0.3046 & 88.34 & -0.27 & 11.93 & 87.86 & 0.27 & 11.87 \\
\hline Overweight & 0.3723 & -0.0653 & 0.1158 & 0.3218 & -17.54 & 31.11 & 86.43 & 12.98 & 23.03 & 63.99 \\
\hline $\begin{array}{l}\text { Obese } \\
2000-2040\end{array}$ & 1.5354 & 1.5370 & -0.3881 & 0.3866 & 100.10 & -25.28 & 25.18 & 66.49 & 16.79 & 16.72 \\
\hline Overweight & 1.1701 & -0.0570 & 0.7186 & 0.5086 & -4.87 & 61.41 & 43.46 & 4.44 & 55.96 & 39.60 \\
\hline Obese & 7.2628 & 6.2578 & 0.1385 & 0.8665 & 86.16 & 1.91 & 11.93 & 86.16 & 1.91 & 11.93 \\
\hline
\end{tabular}


The next three columns (columns 5-7) present the change shown in columns 2 to 4 in percentage terms, with the sum of the per cents equaling 100 per cent of the change. Columns 8 to 10 present per cent of absolute change in the total effect due to rate effect, age, and race/ethnicity.

For all time periods, the total effect (column 1) is positive for overweight and obesity. The results in Table 5 show that change in each of the three factors decomposed has a different effect on the number of overweight and obese persons. This is indicated by the positive as well as negative values shown in the table for 2010-2020, 2020-2040 and 2000-2040. For the total projected time period (2000-2040), the major determinant of change in overweight is the age effect, accounting for 61.4 per cent, followed by the race/ethnicity effect, at 43.5 per cent. The rate effect (population change) had the smallest effect ( -4.8 per cent). For obesity, on the other hand, rate effect is the driving force, with 86.2 per cent of change, followed by race/ethnicity effect (11.9 per cent) and age effect (1.9 per cent). The variations in these rate effects result from the use of a constant rate for overweight, while a somewhat linear rate was used for obesity.

Decomposition of the total effect is also presented for different time intervals for the projected period. For the change in overweight adults, the positive impact of population growth becomes less with time, and even becomes negative between 2010-2020, 2020-2040, and 2000-2040. For obesity the results are different. The impact of population growth on obesity is positive during all four time periods. The impact of rate effects on obesity is more than 100 per cent during the 2000-2040 time period. The impact of rate effects on obesity during the time periods 2000-2010, 2010-2020, and 2020-2040 are 79.3, 88.3, and 100.0 per cent, respectively.

The age effect is more pronounced for overweight status during the projection period than for obesity. This age effect reflects the aging process expected in the population. For example, during the period of 2000-2010, 68.9 per cent of the projected change in the overweight adult population is due to the aging of the population. During all of the time periods, age has the greatest impact on overweight status. Obesity, on the other hand, does not seem to be influenced as much by population aging. During the first two projection periods, the age effect is positive; however, from 2020 to 2040 it is negative. This may be due to the fact that the obesity rate is lower for the $65+$ age group.

Race/ethnicity also has an impact on overweight and obesity. Rapid growth in the minority population has a positive impact on the increase in the numbers of overweight and obese in Georgia. The impact of race/ethnicity on the increase in the number of overweight persons is 27.1 per cent, and the impact on obese persons is 9.8 per cent during 2000-2010. For the period of 2010-2020, the impact of race/ethnicity on the number of overweight persons is 41.5 per cent, while the impact on obese persons is 11.9 per cent. Finally, during 2020 to 2040, the per cent of absolute change due to race/ethnicity accounts for 86.4 per cent of the increase in the number of overweight adults and 25.2 per cent of the number of obese persons.

Looking at the percentages of absolute change, results indicate that the combined effects of age and race/ethnicity increase over time. Thus, whereas these two characteristics account for about 96.0 per cent of the total increase in the number of overweight persons, and 20.7 per cent of the total increase in the number of obese persons, from 2000 to 2010, for 2010 to 2020 these two factors account for 94.8 per cent of the change in the number of overweight persons, and for 12.2 per cent of the change in the number of obese persons. However, for 2020-2040, the effects of these two factors on the number of overweight adults have decreased slightly, while the effects increased significantly for obese adults, compared to those from the period of 2010-2020. The results in Table 5 show that each of the demographic factors (population growth, aging, and diversification) has a different effect on the number of persons who are overweight and obese. In the absence of other 
changes, population aging will increase the number of overweight adults. For 2000-2040, the increase in obese adults would be even greater if it was not for the negative effect of population growth and population aging. Anticipating demographic change is of vital importance for understanding change in these critical health-related statuses.

\section{Conclusions}

The results reported here suggest that demographic change will have an extensive impact on the increase in the number of overweight and obese persons in Georgia. For the overall projected period, the increase in the number of overweight adults will be mainly driven by population aging, with population growth and diversification contributing positively, as well. Obesity, on the other hand, will be fueled by more and more diversification, while population aging and growth lessen the effect of diversification. Independent of the cause, immense increases in overweight and obesity prevalence rates are projected, and related increases in total demand on healthcare and other forms of support can be expected. More than a tripling of the costs associated with overweight and obesity is projected, as well. If the prevalence rates of overweight and obesity develop as assumed here, the annual costs associated with overweight and obesity in Georgia would reach $\$ 21.1$ billion by the year 2040 .

The limitations of this analysis must, however, be recognized. Although the increase in the number of overweight and obese adults in Georgia, and in the United States overall, is expected to continue, only a few projections such as the one presented here exist, that quantify the extent of the increase or the rate of change. A study based on national BRFSS data used a linear time trend to project the prevalence of overweight and obesity among adult males and females in the United States (Flegal et al. 2002). Flegal et al. estimated that among males, the prevalence of overweight would reach 39 per cent by 2020, and the prevalence of obesity would reach 46 per cent. Among females, the prevalence of overweight was estimated to reach 42 per cent by 2020, and the prevalence of obesity was estimated to reach 38 per cent. These estimates are higher than the projections presented here because the estimates in the published study are based on an assumed linear trend. In the present analysis, the changes in rates of prevalence were assumed to decrease over time, since the rapid increase in the prevalence of overweight and obesity in Georgia and the United States that was observed during the 1990s cannot be considered as sustainable. If such rates were to actually occur, nearly everyone would be considered either overweight or obese in the near future. If the prevalence of overweight and obesity continued to follow a positive linear trend in Georgia and reached the levels reported in the published study (Georgia 2005), the associated annual costs of overweight and obesity in Georgia would substantially exceed the projected cost of $\$ 21.1$ billion in 2040. Estimating the change in prevalence rates of overweight and obesity is challenging, because it is impossible to know how the rates are going to develop and when behavioral changes will manifest.

Although we believe the assumptions underlying our analysis are reasonable, given the past and the expected future trends, the projections reported here are based on a number of assumptions and limitations, which must be acknowledged. First of all, it is essential to recognize that projections are subject to considerable inaccuracies, because unforeseen changes may alter the historical patterns on which the projections are based. The cohort component model applies rates to baseline populations. If these rates develop differently from what was assumed, the accuracy of the projections will be affected. Variations in rates could impact, for instance, future population growth, such as declines in the rate of population increase among minority populations. Or, as mentioned before, increases or decreases in the prevalence of overweight and obesity due to changes in the population's dietary 
habits can have negative effects on the outcome of the projection, as well. In addition, the prevalence estimates for overweight and obesity in Georgia are based on self-reported height and weight data, which typically underestimate BMI and can lead to misclassifications (Nieto-Garcia et al. 1990). If the actual prevalence of obesity in Georgia is higher than this study reports, then both the number of overweight and obese adults and the associated costs might be much higher than those presented here. However, both the number of overweight and obese adults and the associated costs might be lower if the actual prevalence of obesity in Georgia is lower than this study reports. We may be overestimating or underestimating the actual number of Georgia adults who are overweight or obese. The reported projections of overweight and obese adults, and costs associated with obesity, will be correct only if the assumptions hold true in the coming years.

It should also be noted that changes in the definition of overweight and obesity may occur over time and that advances in the prevention of, or the possibility of a cure for, overweight and obesity may occur in the next 40 years and may reduce the numbers of overweight and obese adults in Georgia. In addition, it is important to understand the nature of the BMI measure that was used to define overweight and obesity. There is not much difference between a person with a BMI of 29.9 and one with a BMI of 30.1, except that the first individual would be considered overweight and the other one obese. The benefit of the body mass index as a measure for overweight and obesity is its simplicity, yet its limitations must be recognized.

As mentioned before, overweight and obesity have increased immensely in Georgia over the past years. The costs connected with this development are a central aspect. According to a study in 2003 by Finkelstein et al. (2004), the estimated annual costs associated with obesity were $\$ 2.1$ billion, resulting in an annual cost of $\$ 1,431$ per obese person. However, according to a recent study of Dor et al. (2010), the estimated costs associated with overweight men and women are $\$ 432$ and $\$ 524$, respectively (per person) and for obese men and women are $\$ 2,646$ and $\$ 4,879$, respectively; future growth in the overweight and obese population is likely to increase these costs further. Thus, there is a critical need for policies and programs designed to decrease the prevalence of overweight and obesity through both prevention and treatment, in order to address this growing public health problem in Georgia, and in the nation.

The results presented here show the potential magnitude of the increases in the number of overweight and obese persons, along with their demographic dimensions and the costs associated with these increases. In addition, the results also suggest possible factors that should be considered in the development of policies to address the growth in the number of overweight and obese persons. For instance, the important role played by population aging in the change in overweight shows the need to address healthy aging so that overweight does not turn into obesity later in life. In addition, it is evident that although it may not be possible to alter patterns of population growth, projecting where such growth is likely to occur can assist policymakers in locating and sizing service facilities to address the problems associated with overweight and obese status, so that informed decisions can be made. Similarly, the significance of population diversification for obesity, as seen in the decomposition analysis, makes clear that it is essential to target education and prevention programs toward the needs of minority populations. Finally, what is especially critical is to understand that the relationships between such factors as minority status and overweight and obesity stem from social and economic differentials, which are alterable. Programs aimed at reducing socioeconomic disparities may thus also help to reduce the demand for services resulting from overweight or obese status, by reducing the reasons for the disparities in prevalence between minority and other populations. 


\section{Acknowledgements}

The author would like to thank Beverly Pecotte, Dr. Steve Murdock, the editor, and reviewers for their comments and suggestions. Special appreciation is due to Lisa Espinoza, who corrected repeated drafts of this work.

\section{References}

Allison, D.B., K.R. Fontaine, J.E. Manson, J. Stevens, and T.B. Vanitalie. 1999. Annual deaths attributable to obesity in the United States. Journal of the American Medical Association 282:1530-8.

Baskin, M.L., J. Ard, F. Franklin, and D.B. Allison. 2005. Prevalence of obesity in the United States. Obesity Reviews 6(1):5-7.

Calle, E.E., C. Rodriguez, K. WalkerThurmond, and M.J. Thun. 2003. Overweight, obesity, and mortality from cancer in a prospectively studied cohort of U.S. Adults. New England Journal of Medicine 348:1625-38.

CDC (Centers for Disease Control and Prevention). 1991, 1999, 2000, 2001, 2002, 2003, 2007. Behavioral Risk Factor Surveillance System Survey Data. Atlanta, GA: U.S. Department of Health and Human Services, Centers for Disease Control and Prevention. (available online at http://www.cdc.gov/ brfss; last accessed 2010)

Das Gupta, P. 1978. A general method of decomposing a difference between two rates into several components. Demography 15(February):99-112.

Dor, A., C. Ferguson, C. Langwith, and E. Tan. 2010. A Heavy Burden: The Individual Costs of Being Overweight and Obese in the United States. George Washington University, School of Public Health and Health Services, Department of Health Policy.

Finkelstein, E.A., I.C. Fiebelkorn, and G. Wang. 2004. Statelevel estimates of annual medical expenditures attributable to obesity. Obesity Research 12:18-24.

Flegal, K.M., M.D. Carroll, C.L. Ogden, and C.L. Johnson. 2002. Prevalence and trends in obesity among U.S. adults, 1999-2000. Journal of the American Medical Association 288:1723-7.

Flegal, K.M., M.D. Carroll, C.L. Ogden, and L.R. Curtin. 2010. Prevalence and trends in obesity among U.S. adults, 1999-2008. Journal of the American Medical Association 303(3):235-241

Georgia (Georgia Department of Human Resources, Division of Public Health). 2005. Overweight and Obesity in Georgia, 2005. Publication Number DPH05.023HW.

Hollmann, F.W., T.J. Mulder, and J.E. Kallan. 2000. Methodology and Assumptions for the Population Projections of the United States: 1999 to 2100. Population Division Working Paper No. 38. Washington, DC: U.S. Bureau of the Census.

Hoque, N., M.E. McCusker, S.H. Murdock, and D. Perez. 2010. The implications of change in population size, distribution, and composition on the number of overweight and obese adults and direct and indirect cost associated with overweight and obese adults in Texas through 2040. Population Research and Policy Review 29:173-191.

Kitagawa, E.M. 1955. Components of a difference between two rates. Journal of the American Statistical Association 50:1168-94. 
McCusker, M.E., E.J. Sanchez, S.H. Murdock, N. Hoque, and P.P. Huang. 2004. The Burden of Overweight and Obesity in Texas, 2000-2040. (available online at http://www.publichealthgrandrounds.unc.edu/ catch/handout_txCost_Obesity_Report.pdf; last accessed January 2008)

NIH (National Institutes of Health). 1998. Clinical Guidelines on the Identification, Evaluation, and Treatment of Overweight and Obesity in Adults. Bethesda, MD: Department of Health and Human Services, National Institutes of Health, National Heart, Lung, and Blood Institute.

- 2004. National Institute of Diabetes, Digestive and Kidney Diseases. Statistics Related to Overweight and Obesity: The Economic Costs. (available online at http://win.niddk.nih.gov/statistics/ index.htm; last accessed November 2009)

NietoGarcia, F.J., T.L. Bush, and P.M. Keyl. 1990. Body mass definitions of obesity: Sensitivity and specificity using selfreported height and weight. Epidemiology 1(2):146-52.

Obesity in America. 2004. A Handbook on Obesity in America. (available online at http:/ /www. obesityinamerica.org/links/HandbookonObesityinAmerica.pdf; last accessed: January 2008)

Spencer, G. 1984. Projections of the Population of the United States, by Age, Sex, and Race: 1983-2080. Current Population Reports Series P-25, Number 952. U.S. Government Printing Office, Washington, DC.

1986. Projections of the Hispanic Population: 1983-2080. Current Population Reports Series P-25, Number 796. U.S. Government Printing Office, Washington, DC.

-1989. Projections of the Population of the United States, by Age, Sex, and Race/Ethnicity 1988-2080. Current Population Reports Series P-25, Number 1018. U.S. Government Printing Office, Washington, DC.

Sturm, R., J.S. Ringel, and T. Andreyeva. 2004. Increasing obesity rates and disability trends. Health Affairs 23(2):199-205.

U.S. Census Bureau. 2008. Projected Population by Single Year of Age, Sex, Race, and Hispanic Origin for the United States: July 1, 2000 to July 1, 2050 [machine-readable file]. (available online at http://www. census.gov/population/www/projections/files/nation/download/NP2008_D1.csv; last accessed: February 2009)

- 2009. American Community Survey (available online at http://factfinder2.census.gov/faces/ tableservices/jsf/pages/productview.xhtml?pid=ACS_09_1YR_B19013B\&prodType=table last accessed: March 2012).

2011. 2010 Census Summary File 1 (Machine Readable data files). Washington, DC: U.S. Census Bureau 2011.

Wolk, A., G. Gridley, M. Svensson, O. Nyrem, J. McLaughlin, J. Fraumeni, and H.O. Adami. 2001. A prospective study of obesity and cancer risk (Sweden). Cancer Causes and Control 12:13-21. 